\title{
Effects of Ovarian Pathologies and Uterine Inflammations on Adenomyosis in Bitches
}

\author{
Murat Onur Yazlık', Arda Selin Tunc ${ }^{2}$, Hatice Esra Colakoglu', Mehmet Rifat Vural', \\ Sukru Kuplulu' ${ }^{1}$, lbrahim Mert Polat ${ }^{3}$, Burcu $\mathrm{Oz}^{1}$, Serdal Kurt ${ }^{1}$ \& Sevil Atalay Vural ${ }^{2}$
}

\begin{abstract}
Background: Adenomyosis is a non-neoplastic condition, characterized by the presence of endometrial glands or cells in the myometrium. Adenomyosis is defined by post-operative microscopic examination of uterine tissue and a rarely seen infertility problem in bitches. The process of transformation of healthy uterus into adenomiotic uterus is still a mystery. We aimed to determine role of ovarian pathologies and uterine inflammations on pathogenesis of uterine adenomyosis in bitches.

Cases: After ovariohysterectomy, the uteri were fixed and processed by routine methods. Sections were stained with HematoxylinEosin, Masson's trichrome and Periodic-Acid-Schiff and immunohistochemically; with p53 protein, Ki-67, -smooth-muscle actin, cytokeratin-CK 8, 14, 19 antibodies, estrogen and progesterone receptors by Avidin-Biotin-Complex-Peroxidase method. Histopathologically, 7 of the collected tissue samples $(n=38)$ were diagnosed as adenomyosis. There were unilateral $(n=6)$ or bilateral $(n=1)$ adenomyosis in which endometrial glands had broken through the myometrium, and in some cases there were fibromyoma, inflammation, papillary hyperplasia and cysts in glands. Vaginal fibroma, fibromyoma and benign mix tumor ( $\mathrm{n}$ $=1)$, simple carcinoma $(n=3)$, carcinosarcoma $(n=3)$ in mammary gland were determinated histopathologically. In addition to these findings, follicular cysts $(n=4)$, parovarian cyst $(n=1)$, adenocarcinoma and Rete ovarii adenoma were diagnosed in some ovaries. The CK 19 was scored at endometrial glands $(\mathrm{n}=2)$ positively and also, muscle fibers were stained positively with -smooth-muscle actin antibody $(\mathrm{n}=7)$.

Discussion: Adenomyosis is an infertility problem in adult dogs and is hard to detect with routine gynecological examinations. Adenomyosis can be seen unaccompanied by other gynecological problems such as endometritis or leiomyomas, while mammary tumors with adenomyosis have been previously reported in women and in only one case of a bitch. Little is known of the interrelationships between gross pathological and endocrine features of ovarian cysts in bitches. Due to the local hormonal imbalance, most of these ovarian tumors and cystic structures might be accompanied with uterine-vaginal and mammary gland pathologies, cystic endometrial hyperplasia-pyometra, adenomyosis, vaginal fibroma and mammary tumors. The hyperestrogenic metabolic state may promote both the invagination process and the overall spreading of adenomyosis into the myometrium. Adenomyosis is often associated with polyps, anovulation, hyperplasia without cytological atypia, and uterine leiomyoma which are produced by hyperestrogenic states. Prolactin appears to induce adenomyosis in mice and hyperprolactinemia may cause myometrial degeneration/weakness and subsequent endometrial invasion in the presence of ovarian steroids in women. Premature decline in progesterone, a problem ensues with prolactin release which can promote hyperprolactinemia or endogenous prolactin release. In addition to hormonal problems, uterine infections, immune factors and their products like cytokines and inflammatory mediators, oxidative stress and free radical metabolism also might have roles in the occurrence of adenomyosis. In the present study, four of seven adenomyotic uterine tissues had inflammation and 3 of 7 cases had pre-inflammatory changes. Changes in uterine tissues may increase cell infiltration and proliferation as well as the activity of immune cells which may promote development of adenomyosis in bitches. It is therefore possible that a defect in the p53 tumor suppressor gene may play an important role in the de novo neoplastic transformation of adenomyosis. In conclusion, adenomyosis can be observed bilaterally or unilaterally in dogs. Tissue damage under the influence of inflammation or hormonal disturbances might have a role in the occurrence of uterine adenomyosis.
\end{abstract}

Keywords: adenomyosis, bitch, ovarian pathology, uterine inflammation. 


\section{INTRODUCTION}

Adenomyosis is a non-neoplastic hyperplastic lesion, characterized by invagination of proliferating endometrial glands into the myometrium and deeply underlying areas, causing hyperplasia and hypertrophy of surrounding tissues (myometrium) [26]. It has been reported in many species, including women [4], dogs [18], cats [2], rodents [7], cattle [14], pet pigs [9] and primates [17]. Adenomyosis is, coincidentally, defined by post-operative microscopic examination of uterine tissue and is a rarely seen infertility problem in bitches [25].

Adenomyosis can be found together with numerous ovarian, uterine and mammary tissue pathologies; e.g., cystic ovarian disease, polycystic ovaries, pyometra, cystic endometrial hyperplasia, and mammary tumors [21]. Nevertheless, the etiology of adenomyosis is still not clear but hormones, stem/ progenitor cells and age of subjects may have an effect on this pathology [16].

There is an association between adenomyosis and leiomyoma, endometrial hyperplasia and endometrial carcinoma uniquely in women. Adenomyosis is not always a benign condition. Malignant transformation of adenomyotic foci and their hyperplastic changes can be seen but rarely. A possibility with these malignant changes is that cancer in adenomyotic glands arises from within ectopic endometrium [8]. The malignant form usually stains positively for estrogen, progesterone, cyclooxygenase- 2 and cancer antigen 125 . With adenomyotic tissues, also $\alpha$-smooth actin and desmin are constant while vimentin expression is lower than in normal tissue [13]. Ki67, a proliferative factor, increases under the influence of adenomyosis in cows [10]. The tumor suppressor gene, p53, was pres-

Table 1. General information on study animals.

\begin{tabular}{cccc}
\hline Case & Breed & Age & $\begin{array}{c}\text { Location of } \\
\text { Adenomyosis }\end{array}$ \\
\hline 1 & Crossbreed & 14 & Unilateral \\
2 & Crossbreed & 13 & Unilateral \\
3 & Kangal dog & 8 & Unilateral \\
4 & Terrier & 7 & Bilateral \\
5 & German shepherd & 13 & Unilateral \\
6 & American Bulldog & 9 & Unilateral \\
7 & Terrier & 6 & Unilateral \\
\hline
\end{tabular}

ent in $25 \%$ of cases of adenomyosis with carcinoma in women [1]. Usually, cytokeratin (CK)8, CK19 (for epithelial cells) and CK14 (for myoepithelial cells) are used to diagnose mammary tumors.

The process of transformation of healthy uterus into adenomiotic uterus is still a mystery. The main objective of this case paper was to evaluate the role of ovarian pathologies and uterine inflammations on pathogenesis of serendipitously found uterine adenomyosis in bitches, by using clinic and pathomorphologic examination and immunopathological methods.

\section{CASES}

Seven different breed dogs were referred to the Department of Gynecology and Obstetrics at a veterinary teaching hospital with histories of mucoid, mucolytic vulvar discharge in the vagina, neoplastic masses on mammary gland and vagina (Table 1). It is revealed that none of these animals had not been taken any hormone to suppress their sexual activity during clinical anamnesis. Clinic and gynecologic examinations were performed. For the purpose of determination oestrus cycle phase, papanicolaou staining were used. In the vaginal cytology, degenerated neutrophil leucocytes, erythrocytes and several forms of epithelial cells were seen. Also, all animals were in the late diestrus or early anestrus stages of their cycles. Ovariohysterectomy, radical mastectomy or vaginal surgery were performed according to indications. Ovarian, uterine, mammary gland masses, vaginal masses and inguinal lymph nodes were sent for histopathological and immunohistochemical examinations. Tissue samples were diagnosed as adenomyosis histopathologically (Table 1).

All tissues were fixed in $10 \%$ buffered formalin, processed routinely and embedded in paraffin. Paraffin blocks were sectioned at $5 \mu \mathrm{m}$ and stained with hematoxylin and eosin (H\&E), Periodic Acid Schiff (PAS) and Masson's trichrome stains. The PAS was used for characterizing secretions of the uterus and Masson's trichrome for showing the distinction between muscle and epithelial tissue.

Immunohistochemically, the Avidin-Biotin Complex Peroxidase (ABC-P) method was performed on uterine tissues using p53 protein $^{1}, \mathrm{Ki}-67^{2}, \alpha$-smooth actin $^{1}, \mathrm{CK} 8^{3}, \mathrm{CK} 14^{3}$, CK $19^{2}$ antibodies, estrogen ${ }^{4}$ and progesterone receptors ${ }^{4}$ (Table 2). Both single and double (by CK19/ $\alpha$-smooth actin, p53/Ki-6, CK8/ CK14 combinations) staining were done. Avidin-biotin 
M.O. Yazlık, A.S. Tunc, H.E. Colakoglu, et al. 2018. Effects of Ovarian Pathologies and Uterine Inflammations on Adenomyosis in Bitches.

Acta Scientiae Veterinariae. 46(Suppl 1): 315.

Table 2. Antibodies used for uterine staining.

\begin{tabular}{ccccc}
\hline Antibody & Species & Clone & Dilution & $\begin{array}{c}\text { Manu- } \\
\text { facturer }\end{array}$ \\
\hline P53 & Mouse & PAb240 & $1: 200$ & Dako \\
$\begin{array}{c}\text { a-smooth } \\
\text { actin }\end{array}$ & Mouse & 1A4 & $\begin{array}{c}\text { Ready } \\
\text { to use }\end{array}$ & Dako \\
CK8 & Mouse & TS1 & $1: 250$ & $\begin{array}{c}\text { Novo- } \\
\text { castra } \\
\text { sion }\end{array}$ \\
CK14 & Mouse & LL002 & $1: 250$ & $\begin{array}{c}\text { Novo- } \\
\text { castra }\end{array}$ \\
CK19 & Mouse & RCK108 & $\begin{array}{c}\text { Ready } \\
\text { to use }\end{array}$ & $\begin{array}{c}\text { Dako } \\
\text { Dakit }\end{array}$ \\
$\begin{array}{c}\text { Estrogen } \\
\text { receptor }\end{array}$ & Rabbit & SP1 & $1: 250$ & $\begin{array}{c}\text { Thermo } \\
\text { Fisher }\end{array}$ \\
$\begin{array}{c}\text { Proges- } \\
\text { terone } \\
\text { receptor }\end{array}$ & Rabbit & SP2 & $1: 250$ & $\begin{array}{c}\text { Thermo } \\
\text { Fisher }\end{array}$ \\
\hline
\end{tabular}

peroxidase complex kit (Super Sensitive ${ }^{\mathrm{TM}}$ PolymerHRP Detection System/A Biotin-Free Detection System $)^{3}$ and EnVision GI2 Doublestain System Rabbit/ Mouse (DAB+/Permanent Red- Novocastra Peroxidase Detection System $)^{3}$ kits were used. As a chromagen, 3,3- diaminobenzidine (DAB- Novocastra Peroxidase Detection System, RE71-CE) ${ }^{3}$ for single and DAB/ Permanent Red for double staining were selected and

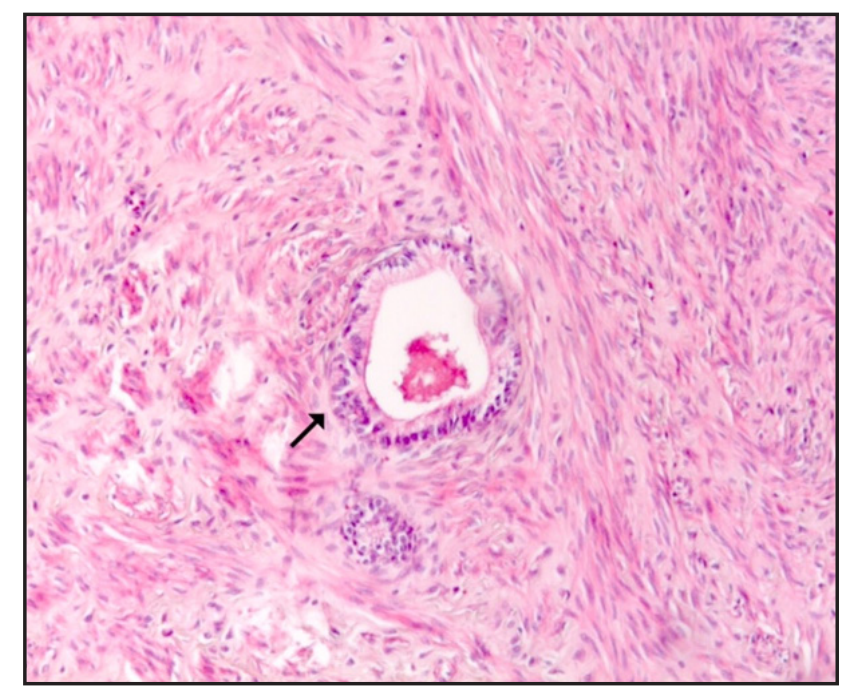

Figure 1. Endometrial glands in the myometrium (H\&E). counterstaining was stained by Harris's hematoxylin 5 . For negative controls, PBS was used instead of each primary antibody. The slides were evaluated under a light microscope (Leica, DM-4000-B) ${ }^{3}$ and photographed (Leica DFC-280) ${ }^{3}$.

\section{Macroscopical findings}

Post-operatively, uterine tissues were presented with cystic formations $(\mathrm{n}=4)$ and a yellowish-white color, and a viscous-mucoid discharge $(n=4)$ in their lumens. Also, tumor was detected only in one uterus and it had $15 \times 8 \times 11 \mathrm{~cm}$ in diameter. Ovaries showed cystic structures between 0.5 and $2 \mathrm{~cm}$ diameters, with varying consistency $(n=5)$ and tumoral masses $(n=2)$ with round-shaped, elastic consistency, grayish-white appearance, and diameters 0.2 to $0.5 \mathrm{~cm}$. Masses in vaginas $(n=2)$ consisted of tumor formations about $3 \times 2 \times 5 \mathrm{~cm}$ in size, a round/oval shape, soft consistency and white color. Masses in mammary gland had between $1 \times 1 \times 0.5$ and $18 \times 10 \times 10 \mathrm{~cm}(\mathrm{n}=4)$ in diameters and inguinal lymph nodes were enlarged $(n=2)$.

\section{Histopathological findings}

Microscopic examinations of uterine tissues were seen an intra-myometrial collection of endometrial glandular epithelium surrounded by typical stromal cells (Figure $1 \&$ Figure 2). Adenomyotic areas were located unilaterally $(n=6)$ and bilaterally $(n=1)$ in the horns of the uteri. Hyperplastic lesions $(n=2)$ and inflammation $(n=4)$ were seen in uterine tissues. A neoplastic formation; Fibromyoma was detected only in one uterine tissue sample and not related to adenomyosis. The ovaries were irregular and had cysts

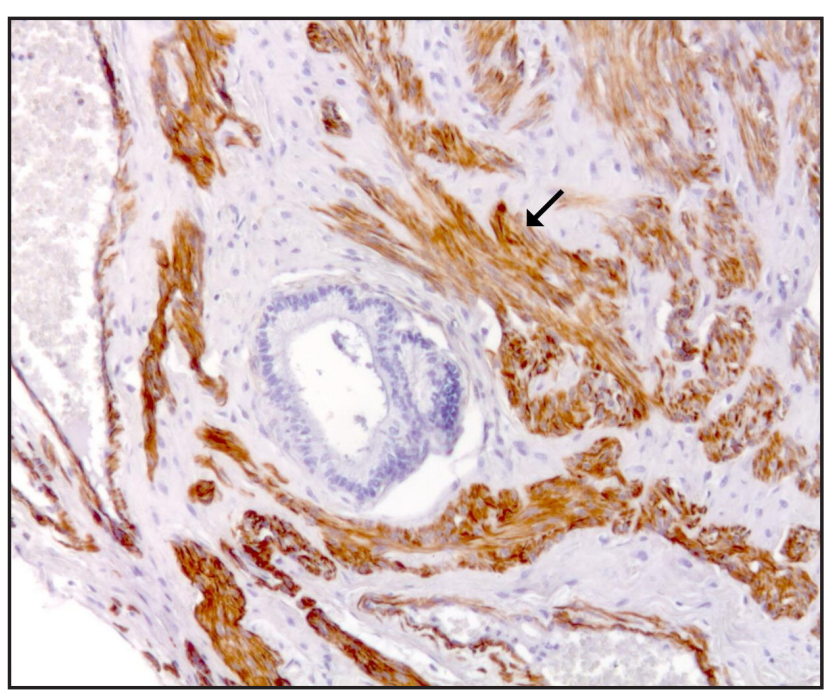

Figure 2. Masson's trichrome (x400). 
M.O. Yazlık, A.S. Tunc, H.E. Colakoglu, et al. 2018. Effects of Ovarian Pathologies and Uterine Inflammations on Adenomyosis in Bitches.

Acta Scientiae Veterinariae. 46(Suppl 1): 315.

Table 3. Histopathological findings of ovaries, uteri, vaginas, mammary glands and inguinal lymph nodes in adenomyotic bitches.

\begin{tabular}{|c|c|c|c|c|c|}
\hline No & Ovaries & Uterus & Vagina & Mammary Gland & $\begin{array}{l}\text { Inguinal } \\
\text { lymph node }\end{array}$ \\
\hline 1 & $\begin{array}{c}\text { Follicular cysts } \\
\text { Paraovarian cysts } \\
\text { Rete Ovarii Adenoma }\end{array}$ & $\begin{array}{l}\text { Hyperplasia in } \\
\text { glands }\end{array}$ & Fibroma & - & - \\
\hline 2 & $\begin{array}{l}\text { Multicystic ovaries } \\
\text { Endometriosis in ovary }\end{array}$ & $\begin{array}{l}\text { Purulent } \\
\text { myometritis } \\
\text { Atrophy in } \\
\text { endometrium }\end{array}$ & Fibromyoma & - & - \\
\hline 3 & Adenocarcinoma & $\begin{array}{l}\text { Subacute cystic } \\
\text { endometritis }\end{array}$ & - & - & - \\
\hline 4 & - & $\begin{array}{l}\text { Papillary hyper- } \\
\text { plasia in glands }\end{array}$ & - & $\begin{array}{l}\text { Carcinosarcoma } \\
\text { Subacute mastitis }\end{array}$ & $\begin{array}{l}\text { Lymphadeni- } \\
\text { tis simplex }\end{array}$ \\
\hline 5 & Follicular cysts & $\begin{array}{l}\text { Fibromyoma } \\
\text { Purulent cystic } \\
\text { metritis }\end{array}$ & - & $\begin{array}{c}\text { Carcinosarcoma } \\
\text { Simple Carcinoma (papillary) }\end{array}$ & - \\
\hline 6 & Follicular cysts & $\begin{array}{l}\text { Acute cystic ca- } \\
\text { tarrhal } \\
\text { endometritis }\end{array}$ & - & $\begin{array}{c}\text { Simple Carcinoma (Tubulopapillary) } \\
\text { Carcinosarcoma } \\
\text { Simple Carcinoma } \\
\text { (CysticTubulopapillary) }\end{array}$ & $\begin{array}{l}\text { Lymphad- } \\
\text { enitis hemor- } \\
\text { rhagica }\end{array}$ \\
\hline 7 & Follicular cysts & Cysts & - & Benign mix tumor & - \\
\hline
\end{tabular}

$(\mathrm{n}=5)$ and tumors $(\mathrm{n}=2)$. Tumors in the vaginas $(\mathrm{n}$ $=2)$, mammary gland tumors $(n=4)$ and inflammations in inguinal lymph node $(\mathrm{n}=2)$ were encountered. All pathologic lesions detected by histopathological examination are shown in Table 3.

\section{Immunohistochemical findings}

p53, Ki67, CK8 and CK14 were not detected in all adenomyotic foci and adjacent healthy endometrium in both single and double staining. Also, adenomyotic foci were negative for the expression of estrogen and progesterone receptors. CK19 was observed in endometrial glands $(n=2)$ with adenomyosis and $\alpha$-smooth actin was positive in the muscle fibers of all uterine tissues in both single and double staining $(\mathrm{n}=$ 7) [Figure $2 \&$ Figure 4].

\section{DISCUSSION}

Adenomyosis is an infertility problem in adult dogs and is hard to detect with routine gynecological examinations. It was first diagnosed coincidentally in the course of histopathologic examination of uteri [25]. However, adenomyosis can be seen unaccompanied by other gynecological problems like endometritis or leiomyomas, while mammary tumors with adenomyosis have been previously reported in women [26] and in only one case of a bitch [21]. Adenomyosis is generally found unilaterally in bitches, however, in one case it was seen bilaterally in the present study. All of the adenomyotic cases were obtained coincidentally in the present study and taken from animals suffering from cystic endometrial hyperplasia-pyometra, vaginal fibromyoma and mammary gland tumors. None of the cases showed any symptoms from the point of adenomyosis. Also, abdominal USG and x-ray results did not show any signs of adenomyosis. Ovarian cysts, ovarian tumors and/or cystic hyperplasia-inflammation in uterine tissue were the most common findings.

Uterine lesions present after dysregulation of cyclicity and endocrine pathways [10] or the unbalanced secretion of ovarian steroids [14]. Ovarian cysts were frequently seen along with adenomyosis in women. In the bitch, there are different types of ovarian cysts called follicular cysts, cysts of subsurface epithelial structures, cystic rete ovarii, lutein cysts, and cystic corpora lutea. It is known that ovarian cysts can persist for years in ovarian tissues that may be endocrinologically active or inactive [20]. Follicular cysts are known to be endocrinologically active which means they produce estradiol 17- $\beta$ and progesterone. Despite their clinical significance, little is known of the interrelationships between gross pathological and endocrine features of ovarian cysts in bitches [12]. 
In the present study, the majority of ovarian cysts were between 0.5 to $2 \mathrm{~cm}$ in diameter. All animals with ovarian pathology, corresponding to late diestrusearly anestrus, and were submitted to the clinic due to vulvar discharge outside of the physiologic proestrusestrus stage. However, estradiol-17 $\beta$ and progesterone concentrations in these cystic fluids and blood plasma could not be measured. However, it was reported that no correlation was found between plasma estradiol$17 ß$ and progesterone concentrations and the number ovarian cysts $\leq 0.5 \mathrm{~cm}$ diameter; and that the endocrine activity of cysts located on the same ovary was independent of other cysts [11]. Also, formation of cystic ovarian follicles might be a result of inefficient $\mathrm{LH}$ stimulation, absence of $\mathrm{LH}$ receptors in their structures or the carryover effect of uterine endotoxins like in cattle [22]. The possibility of ovulation of follicles that are too small, but which contain LH receptors, could explain why animals with cystic ovaries exhibited physiologic cycle activity.

Adenocarcinoma and cystic rete ovarii adenoma originate from ovarian epithelial surfaces. Epithelial ovarian tumors are found less coincidentally than those of mesenchymal origin. Due to the local hormonal imbalance, most of these ovarian tumors and cystic structures might be accompanied with uterinevaginal and mammary gland pathologies, such as cystic endometrial hyperplasia-pyometra, adenomyosis, vaginal fibroma and mammary tumors [28].

In the human endometrium adenomyotic cases, expression of $\mathrm{LH}$, estrogen and progesterone receptors is greater than in the normal endometrium [5]. The hyperestrogenic metabolic state may promote both

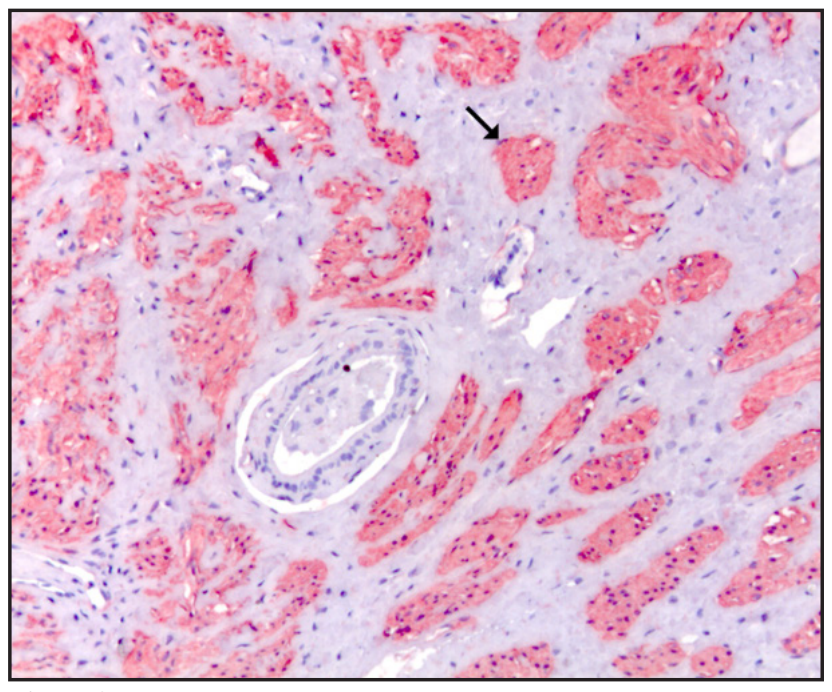

Figure 3. Positivity of alpha smooth actin at muscle fibers ABC-P. the invagination process and the overall spreading of adenomyosis into the myometrium. Adenomyosis is often associated with polyps, anovulation, hyperplasia without cytological atypia, and uterine leiomyoma which are produced by hyper-estrogenic states. A hyperestrogenic metabolic state may promote the invagination process [1]. However, our results were not similar to these findings. Neither estrogen nor progesterone receptors were detected in present study. The main reason for this discrepancy is that the endocrine mechanism of the canine cycle and its hormone profile is totally different from that of humans and other mammals. The absence of steroid hormone receptors in uteri is a physiological state in dogs during the late diestrus and early anestrus periods [3]. All of the tissues examined in the present study were taken from the late diestrus or early anestrus periods. Also, bitches are normally under the influence of prolactin from the second phase of the diestrus period. We have no data about prolactin secretion and adenomyosis from our results. However, prolactin appears to induce adenomyosis in mice [19] and hyperprolactinemia may cause myometrial degeneration/weakness and subsequent endometrial invasion in the presence of ovarian steroids in women [6]. In dogs with premature decline in progesterone, a problem ensues with prolactin release which can promote hyperprolactinemia or endogenous prolactin release; this is especially true in bitches that had ovarian pathologies.

In addition to hormone-dependent problems, uterine infections, immune factors and their products like cytokines and inflammatory mediators, oxidative stress and free radical metabolism also might have roles

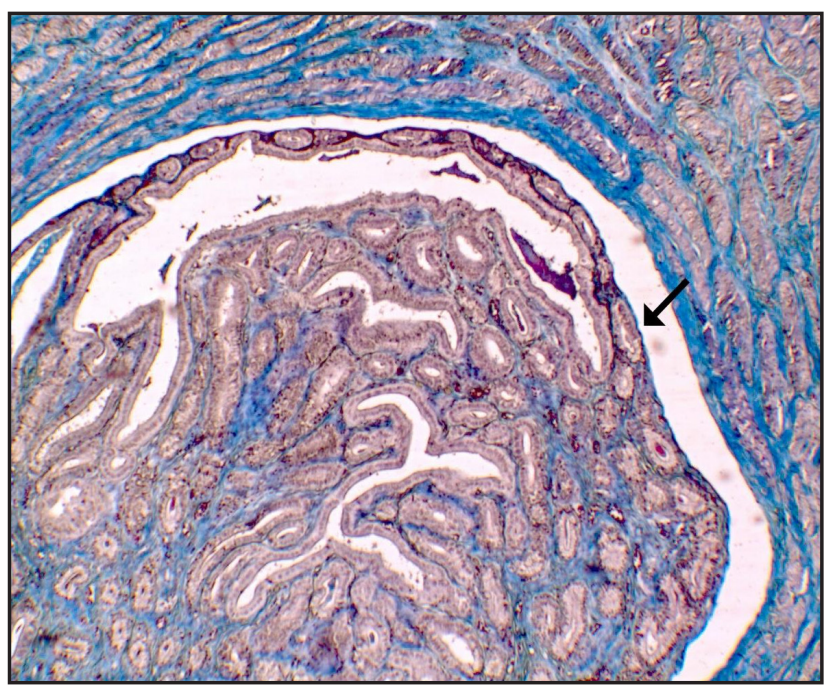

Figure 4. CK19/ alpha smooth actin - Double Staining (x400). 
in the occurrence of adenomyosis. Also it is proved that cytokine production was altered in mononuclear cells derived from adenomyotic tissue in women [24]. That study showed a significant increase in interferon $\gamma$ (IFN-Y), IFN $\alpha$, interleukin-1 $\beta$ (IL-1 $\beta$ ) and tumor necrosis factor $\alpha$ (TNF- $\alpha$ ) concentrations as well as a decrease in IL- 8 concentration. Interleukin- 8 is a major regulator of immune responses as an anti-inflammatory modulator. The main reason for such changes might be over-stimulation of the immune system under the influence of severe inflammation. Pattern recognition receptors, such as Toll-like receptors (TLR-2 and TLR4 ), on endometrial cells detect pathogen-associated molecular patterns (PAMPs), leading to release of nuclear factor kappa B (NF- $\mathrm{kB}$ ) from these cells [23]. This factor is also activated by growth factors and oxidative stress. NF- $\kappa B$ is a pivotal transcriptional factor with roles in gene modulation during inflammation, as well as in proliferation, apoptosis, invasion, angiogenesis and other cellular functions. Also, it promotes the secretion of cytokines, such as TNF- $\alpha$, IL- $1 \beta$, IL-6 and chemokines such as IL- 8 and prostaglandin-E in canine uteri with cystic endometrial hyperplasiapyometra complex [23]. It has been reported that NF$\kappa \mathrm{B}$ DNA binding activity was higher in women with uterine adenomyosis [15]. There is no such report for adenomyosis in the bitch. In the present study, four of seven adenomyotic uterine tissues had inflammation and 3 of seven cases had pre-inflammatory changes. These changes in uterine tissues may increase cell infiltration and proliferation as well as the activity of immune cells. Such changes may promote development of adenomyosis in bitches.

There are a few previous immunohistochemical studies on this subject. Actin and desmin are usually found in smooth muscle cells in adenomyotic foci and normal myometrium. Immunohistochemical characteristics of uterine adenomyosis using antibodies against AE1/AE3, vimentin, actin, desmin, estrogen and progesterone were defined [5]. Actin similarly was strongly positive in our study, which used CK19, CK8 and CK14 for glandular epithelium instead of AE1/ AE3. The CK19 was positive for endometrial glands in only two cases but CK8 and CK14 were negative and epithelial-mesenchymal interactions might be involved. Also one research group failed to find $\mathrm{p} 53$ by immunohistochemistry in adenomyotic foci [27], which supports our findings. However, p53 was present in $25 \%$ of cases of adenomyosis with carcinoma [27]. It is therefore possible that a defect in the p53 tumor suppressor gene may play an important role in the de novo neoplastic transformation of adenomyosis [1]. Ki67 is a proliferative factor and is mostly present in malignant tumors and sometimes in hyperplasia [10], but in our study no positive reactions were observed for Ki67.

Seven canine cases of adenomyosis were described and evaluated clinically, pathomorphologically and immunopathologically. Our results showed that adenomyosis can be observed bilaterally or unilaterally in dogs. Ovarian pathologies and uterine inflammations might have a role in the occurrence of adenomyosis in the bitch. Further research is needed to characterize the etiopathogenic mechanisms of adenomyosis, requiring additional molecular-endocrinologic and mechanistic studies.

\section{MANUFACTURERS}

${ }^{1}$ Dako Denmark A/S. Glostrup, Denmark.

${ }^{2}$ Lab Vision. Fremont, CA, USA.

${ }^{3}$ Leica. Wetzlar, Germany.

${ }^{4}$ Thermo Fisher Scientific. Waltham, MA, USA.

${ }^{5}$ Merck KGaA. Darmstadt, Germany.

Acknowledgements. Preliminary version of this article is accepted for poster presentation (PW27 - The evaluation of cell differentiation markers in dog adenomyosis) in 18th International Congress on Animal Reproduction (ICAR) 26-30 June 2016, Tours, France.

Declaration of interest. The authors report no conflicts of interest.

\section{REFERENCES}

1 Bergeron C., Amant F. \& Ferenczy A. 2006. Pathology and physiopathology of adenomyosis. Best Practice \& Research Clinical Obstetrics \& Gynaecology. 20: 511-521.

2 Bulman-Fleming J. 2008. A rare case of uterine adenomyosis in a Siamese cat. The Canadian Veterinary Journal. 49: 709-712.

3 Concannon P.W. 2011. Reproductive cycles of the domestic bitch. Animal Reproduction Science. 124: 200-210.

4 Di Donato N., Montanari G., Benfenati A., Leonardi D., Bertoldo V., Monti G., Raimondo D. \& Seracchioli R. 2014. Prevalence of adenomyosis in women undergoing surgery for endometriosis. The European Journal of Obstetrics \& Gynecology and Reproductive Biology. 181: 289-293.

5 Ferenczy A. 1998. Pathophysiology of adenomyosis. Human Reproduction Update. 4: 312-322. 
M.O. Yazlık, A.S. Tunc, H.E. Colakoglu, et al. 2018. Effects of Ovarian Pathologies and Uterine Inflammations on Adenomyosis in Bitches.

Acta Scientiae Veterinariae. 46(Suppl 1): 315.

6 Ficicioglu C., Tekin H.I., Arioglu P.F. \& Okar I. 1995. A murine model of adenomyosis: the effects of hyperprolactinemia induced by fluoxetine hydrochloride, a selective serotonin re-uptake inhibitor, on adenomyosis induction in Wistar albino rats. Acta Europaea Fertilitatis. 26: 75-79.

7 Guttner J. 1980. Adenomyosis in mice. Zeitschrift Fur Versuchstierkunde. 22: 249-251.

8 Habiba M. \& Benagiano G. 2016. Adenomyosis and endometrial carcinoma. In: Habiba M. \& Benagiano G. (Eds). Uterine Adenomyosis. Switzerland: Springer International Publishing, pp.153-161.

9 Illha M.R., Newman S. J., Van Amstel S., Fecteau K.A. \& Rohrbach B.W. 2010. Uterine lesions in 32 female miniature pet pigs. Veterinary Pathology. 47: 1071-1075.

10 Katkiewicz M., Wierzchon M. \& Boryczko Z. 2005. Adenomyosis cows' uterus - latent cause of infertility? Medycyna Weterynaryjna. 61: 1378-1381.

11 Knauf Y., Bostedt H., Failing K., Knauf S. \& Wehrend A. 2014. Gross pathology and endocrinology of ovarian cysts in bitches. Reproduction in Domestic Animals. 49: 463-468.

12 Knauf Y. \& Wehrend A. 2010. Ovarian cysts in the bitch. Tierärztliche Praxis. 38: 333-340.

13 Koike N., Tsunemi T., Uekuri C., Akasaka J., Ito F., Shigemitsu A. \& Kobayashi H. 2013. Pathogenesis and malignant transformation of adenomyosis. Oncology Reports. 29: 861-867.

14 Korzekwa A.J., Bah M., Gęstwicka M., Socha B. \& Skarżyński D.J. 2013. Adenomyosis in the bovine uterus: correlation between frequency, age, and 17ß-estradiol-progesterone equilibrium. Theriogenology. 79: 165-172.

15 Li B., Chen M., Liu X. \& Guo S.W. 2013. Constitutive and tumor necrosis factor- $\alpha$-induced activation of nuclear factor- B in adenomyosis and its inhibition by andrographolide. Fertility and Sterility. 100: 568-577.

16 Łupicka M., Socha B., Szczepańska A. \& Korzekwa A. 2015. Expression of pluripotency markers in the bovine uterus with adenomyosis. Reproductive Biology and Endocrinology. 13: 110-123.

17 Mackenzie W.F. \& Casey H.W. 1975. Animal model of human disease. Endometriosis. Animal model: endometriosis in rhesus monkeys. The American Journal of Pathology. 80: 341-344.

18 Mir F., Fontaine E., Albaric O., Greer M., Vannier F., Schlafer D.H. \& FontbonneA. 2013. Findings in uterine biopsies obtained by laparotomy from bitches with unexplained infertility or pregnancy loss: an observational study. Theriogenology. 79: 312-322.

19 Mori T. \& Nagasawa H. 1983. Mechanisms of development of prolactin-induced adenomyosis in mice. Acta Anatomica. 116:46-54.

20 Olson P.N., Wrigley R.H., Husted P.W., Bowen R.A. \& Nett T.A. 1989. Persistent estrus in the bitch. In: Ettinger S.J., Feldman E.C. \& Cote E. (Eds). Textbook of Veterinary Internal Medicine. Philadelphia: WB Saunders, pp.1792-1796.

21 Perez-Marin C.C., Molina L., Dominguez J.M., Millan Y. \& De Las Mulas J.M. 2008. Incidental finding of uterine adenomyosis in a bitch with reproductive disorders: a case report. Veterinarni Medicina. 53: 636-640.

22 Polat .M., Alçi ir E., Pekcan M., Vural S.A., Özenç E., Canatan H.E., Yazlik M.O. \& Vural M.R. 2015. Characterization of transforming growth factor beta superfamily, growth factors, transcriptional factors, and lipopolysaccharide in bovine cystic ovarian follicles. Theriogenology. 84: 1043-1052.

23 Silva E., Leitão S., Henriques S., Kowalewski M.P., Hoffmann B., Ferreira-Dias G. \& Mateus L. 2010. Gene transcription of TLR2, TLR4, LPS ligands and prostaglandin synthesis enzymes are up-regulated in canine uteri with cystic endometrial hyperplasia-pyometra complex. Journal of Reproductive Immunology. 84: 66-74.

24 Sotnikova N., Antsiferova I. \& Malyshkina A. 2002. Cytokine network of eutopic and ectopic endometrium in women with adenomyosis. American Journal of Reproductive Immunology. 47: 251-255.

25 Stockun-Gautschi N.M., Guscetti F., Reichler I.M., Geissbuhler U., Braun S.A. \& Arnold S. 2001. Identification of focal adenomyosis as a uterine lesion in two dogs. Journal of Small Animal Practice. 42: 413-416.

26 Struble J., Reid S. \& Bedaiwy M.A. 2016. Adenomyosis: A clinical review of a challenging gynecologic condition. Journal of Minimally Invasive Gynecology. 23: 164-185.

27 Taskin M., Lallas T.A., Shevchuk M. \& Barber H.R. 1996. P53 expression in adenomyosis in endometrial carcinoma patients. Gynecologic Oncology. 62: 241-246.

28 Yotov S., Simeonov R., Dimitrov F., Vassilev N., Dimitrov M. \& Georgiev P. 2005. Papillary ovarian cystadenocarcinoma in a dog: clinical communication. Journal of the South African Veterinary Association. 76: 43-45. 